\title{
Studies on lithofacies sequences in the Hoanh Bo basin, Quang Ninh province by using Markov chain model and Entropy function
}

\author{
Hung The Khuong $1{ }^{*}$, Tra Thuy Thi Lai ${ }^{2}$ \\ ${ }^{1}$ Hanoi University of Mining and Geology, Hanoi, Vietnam \\ 2 Phuong Dong University, Hanoi, Vietnam
}

\section{ARTICLE INFO \\ Article history: \\ Received 18 $18^{\text {th }}$ Sept. 2021 \\ Revised 29th Dec. 2021 \\ Accepted $11^{\text {th }}$ Jan. 2022}

Keywords:

Entropy function,

Hoanh Bo basin,

Lithofacies,

Markov chain,

Quang Ninh.

\section{ABSTRACT}

The succession of lithofacies in the Dong Ho and Tieu Giao formation's Hoanh Bo basin was statistically analyzed using the modified Markov chain model and the function of Entropy. Based on the field definitions, petrographic investigation, and their borehole logs, the lithofacies study was carried out to determine the sediment deposition system and the deposition environment. Seventeen sub - lithofacies organized within the succession are recognized in three lithofacies associations. The analysis result of the Markov chain and chi-square or $X^{2}$ test indicates that the deposition of the lithofacies is a non - markovian process and represents cyclic deposition of asymmetric fining - upward. To evaluate the randomness of the occurrence of lithofacies in a succession, entropy analysis was performed. Each state is associated with two types of entropy; one is relevant to the Markov matrix expressing upward transitions (entropy after deposition) and the other is relevant to the downward transition matrix (entropy before deposition). The energy regime calculated from the maximum randomness entropy analysis indicates that changing patterns in a deposition has resulted from rapid to steady flow. This results in a change in the depositional pattern from alluvial - fluvial to lacustrine environments, specifically from conglomerate facies (A1) $\rightarrow$ sandstone facies (A2) $\rightarrow$ fine-grained and non - debris facies (A3).

Copyright (C) 2022 Hanoi University of Mining and Geology. All rights reserved.

${ }^{*}$ Corresponding author

E - mail: khuongthehung@humg.edu.vn

DOI: 10.46326/JMES.2022.63(1).02 


\title{
Tạp chí Khoa học Kỹ thuật Mỏ - Địa chất
}

Trang điện tử: http://tapchi.humg.edu.vn

\section{Nghiên cứu trình tự tướng đá trầm tích khu vực thung lũng Hoành Bồ, Quảng Ninh bằng mô hình xích Markov và Entropy}

\author{
Khương Thế Hùng ${ }^{1,}{ }^{*}$, Lại Thị Thúy Trà ${ }^{2}$ \\ ${ }^{1}$ Trường Đại học Mỏ - Địa chất, Hà Nội, Việt Nam \\ ${ }^{2}$ Trường Đại học Phương Đông, Hà Nội, Việt Nam
}

\begin{abstract}
THÔNG TIN BÀI BÁO
Quá trình:

Nhận bài 18/9/2021

Sửa xong 29/12/2021

Chấp nhận đăng 11/01/2022

Tù khóa:

Hàm entropy,

Quảng Ninh,

Thung lũng Hoành Bồ,

Tướng đá trầm tích,

Xích Markov.

\section{TÓM TẮT}

Tướng đá ở khu vực thung lũng Hoành Bồ, Quảng Ninh thuộc hệ tầng Đồng Ho và Tiêu Giao được nghiên cúu thống kê bằng xích Markov và hàm Entropy. Việc phân tích các tướng đá dựa trên mô tả thực đia, khảo sát thach học và phân tích các thiết đồ lỗ khoan. 17 loại tướng chi tiết được sắp xếp vào ba loại tổ hợp tướng trầm tích trong khu vực nghiên cứu. Kết quả phân tích xích Markov ấn đinh, tiêu chuẩn chi bình phuoong hay kiểm tra $\chi^{2}$ cho múc độ tin cậy 0,5\% chỉ ra quá trình lắng đọng trầm tích là không tuần hoàn và biểu diễn quá trình trầm tích không đối xúng theo chu kỳ tù̀ hạt thô lên hạt mịn. Phân tích entropy thực hiện nhằm đánh giá tính ngầu nhiến sự xuất hiện các tuớng đá trong một chuỗi liên tiếp. Hai loại entropy có liên quan đển mọi trạng thái: i) liên quan đến ma trận Markov thể hiện các chuyển đổi hướng lên (entropy sau trầm tích) và ii) liên quan đến ma trận biểu thị các chuyển đổi đi xuông (entropy trước trầm tích). Chế độ năng lượng tính toán từ phân tích entropy cho thấy tính ngẫu nhiên tối đạ, gợi ý sự thay đổi các thông số trầm tích là kết quả của dòng chảy nhanh đến ổn định. Điều này dẫn đến sự thay đổi tướng trầm tích tù̀ môi trường sông sang môi trường đầm hồ, cụ thể từ tướng cuội kết (A1) $\rightarrow$ tướng cát kết (A2) $\rightarrow$ tướng hạt mịn và không mảnh vụn (A3).
\end{abstract}

C 2022 Trường Đại học Mỏ - Địa chất. Tất cả các quyền được bảo đảm.

\section{Giới thiệu}

Hoành Bồ là khu vực nằm trong cấu trúc vùng Đông Bắc, phía tây giáp với Uông Bí, phía bắc giáp với tỉnh Bắc Giang, phía đông giáp với Cẩm Phả, phía nam giáp với làng Yên Lập, Thành phố Ha Long, tỉnh Quảng Ninh. Đây là khu vực phổ biến các trầm tích nguồn gốc lục nguyên có màu xám,

\footnotetext{
*Tác giả liên hệ

E - mail: khuongthehung@humg.edu.vn DOI: 10.46326/JMES.2022.63(1).02
}

nâu xám đến nâu đỏ, cấu tạo phân lớp mỏng đến vừa. Thành phần thạch học của các trầm tích chủ yếu là cuội kết, cát kết, sét kết và bột kết, phân bố rộng khắp thung lũng.

Nghiên cứu về tính liên tục của lớp trầm tích trong các mặt cắt thạch địa tầng với mô hình ngẫu nhiên của quá trình trầm tích biểu diễn như là quá trình Markov rời rạc (xích Markov) có lịch sử khá dài. Các công bố đầu tiên xuất hiện vào những năm 1960 (Vistelius và Faas, 1965; Vistelius và Feygelson, 1965; Krumbein, 1967; Potter và Blakely, 1968), đã đạt được những thành công nhất định trong nghiên cứu sự biến thiên chiều 
dày của cột địa tầng và đưa ra những giả thuyết về quá trình hình thành các lớp trầm tích. Những công bố tiếp theo đề cập đến các phương pháp nghiên cứu chuyên sâu, cho phép nhận ra đặc điểm cụ thể các ứng dụng địa chất của xích Markov và sự chính xác trong giải thích các kết quả tính toán (Doktor và nnk., 2010; Soto và nnk., 2014; Cao và nnk., 2022). Từ những thành công trên xích Markov được xem như một công cụ chuẩn cho phân tích trầm tích. Vì vậy, việc ứng dụng xích Markov và hàm Entropy trong nghiên cứu trình tự tướng đá từ các trầm tích khu vực thung lũng Hoành Bồ, Quảng Ninh là khả thi và cần thiết.

Nghiên cứu được thực hiện dựa trên kết quả khảo sát các vết lộ và tài liệu 12 thiết đồ lỗ khoan (Dương, 1960) để tìm ra tính chu kỳ trầm tích ở thung lũng Hoành Bồ bằng xích Markov và hàm Entropy. Mục đích của bài viết nhằm: 1) đánh giá đặc tính trầm tích theo chu kỳ thống kê bằng phân tích xích Markov; so sánh tính chu kỳ (nếu có) theo thời gian và không gian; 2 ) đánh giá mức độ sắp xếp hoặc chế độ năng lượng của quá trình lắng đọng các tướng trầm tích bằng hàm Entropy; 3) nhận biết môi trường trầm tích phổ biến của thung lũng Hoành Bồ.

\section{Khái quát về đặc điểm địa chất khu vực}

Thung lũng Hoành Bồ nằm giữa hai đứt gãy chính là đứt gãy Chí Linh - Hòn Gai về phía nam và đứt gãy Trung Lương về phía bắc (Hình $1 \mathrm{~A}$ $B)$. Hai đứt gãy này được đánh giá có vai trò quan trọng trong tiến trình hình thành của thung lũng.

Đứt gãy Trung Lương có dạng một cánh cung với mặt trượt nghiêng về phía nam, hướng dốc $60 \div 90^{\circ}$. Trong thời kỳ Mezozoi muộn và Kainozoi sớm, đứt gãy này hoạt động như một đứt gãy nghịch, tạo ra các mặt trượt gần như thẳng đứng dốc dần về đông bắc (Lê,, 2003). Trong Kainozoi, đứt gãy Trung Lương hoạt động như một đứt gãy trượt bằng phải (Vũ, 2002).

Đứt gãy Chí Linh - Hòn Gai là một đứt gãy trượt bằng kéo dài với khoảng cách hơn $200 \mathrm{~km}$. Mặt trượt nghiêng về bắc với hướng dốc $40^{\circ}$, góc dốc gần $80^{\circ}$ (Vũ, 2002; Lê, 2003). Trong Pliocen đến Đệ tứ, đứt gãy thay đổi phương dịch chuyển từ trượt bằng trái (pha sớm) tới trượt bằng phải (pha muộn) (Nguyễn, 2004). Ngoài ra, thung lũng Hoành Bồ cũng bị gây nhiễu bởi nhiều đứt gãy nhỏ có phương khác nhau như phương đông bắc - tây nam, hầu hết vuông góc với đứt gãy chính.

Thung lũng Hoành Bồ được lấp đầy bởi các trầm tích hệ tầng Đồng Ho và Tiêu Giao (Hình 1C). Sau quá trình trầm tích, khu vực nghiên cứu bị nén ép với sự kích hoạt lại của các đứt gãy đã có từ trước, dẫn đến biến dạng giòn và nghịch đảo. Ngoài ra, thung lũng Hoành Bồ còn bị phức tạp bởi các đứt gãy có phương khác nhau từ đông bắc sang tây nam, gần như song song với đứt gãy chính.

Hệ tầng Đồng Ho được các nhà địa chất Pháp phát hiện từ những năm 20 của thế kỷ trước, nhưng những văn liệu này ít được phổ cập. Phạm (1969) khi đo vẽ bản đồ địa chất dải than vùng Quảng Ninh đã xác lập “điệp Đồng Ho" ở khu vực Đồng Ho và Hoành Trới thuộc huyện Hoành Bồ, tỉnh Quảng Ninh. Ở vùng nghiên cứu, hệ tầng lộ ra khá nhỏ về phía đông, thành phần chủ yếu là cát kết, bột kết, phiến sét chứa than. Chiều dày hệ tầng biến thiên khá nhiều, trong khoảng $140 \div 430 \mathrm{~m}$. Hệ tầng Đồng Ho nằm không chỉnh hợp trên hệ tầng Hòn Gai, nằm chỉnh hợp với hệ tầng Tiêu Giao.

Tuổi của hệ tầng Đồng Ho vẫn còn đang được tranh luận, tuy nhiên, hầu hết các nhà địa chất coi nó là Miocen. Phạm và nnk. (1999) đã tìm thấy một tập hợp hệ thực vật và kết luận trầm tích Đông Ho có tuổi Oligocen. Sau đó, ý kiến này đã được xác nhận bởi các công bố tiếp theo và được xuất bản trong nhiều chuyên khảo khác nhau (Tống và Vũ, 2005; Trần và Vũ, 2009), nhưng vẫn chưa có bằng chứng rõ ràng. Tuy nhiên, Wang (trong Đặng, 2007) đã công bố các bằng chứng về tuổi Miocen của hệ tầng Đông Ho dựa trên kết quả phân tích tại Viện Địa chất và Cổ sinh Nam Kinh, (Trung Quốc).

Hệ tầng Tiêu Giao tương ứng với điệp Tiêu Giao (Trịnh và Trịnh, 1975), trong vùng nghiên cứu hệ tầng lộ ra ít ở phía đông. Thành phần chủ yếu là cát kết gắn kết yếu, sét kết, bột kết,... phần dưới cùng là nơi tiếp xúc với các trầm tích cổ có lớp cuội kết cơ sở mỏng với thành phần thạch học của cuội chủ yếu là thạch anh. Trong đá thường biểu hiện tính phân lớp ngang và xiên thoải. Một số nơi trong đá hạt mịn có các hóa đá thực vật bảo tồn xấu. Các đá trên có quan hệ chỉnh hợp với hệ tầng Đồng Ho. Chiều dày hệ tầng khoảng $250 \div 300$ m. 


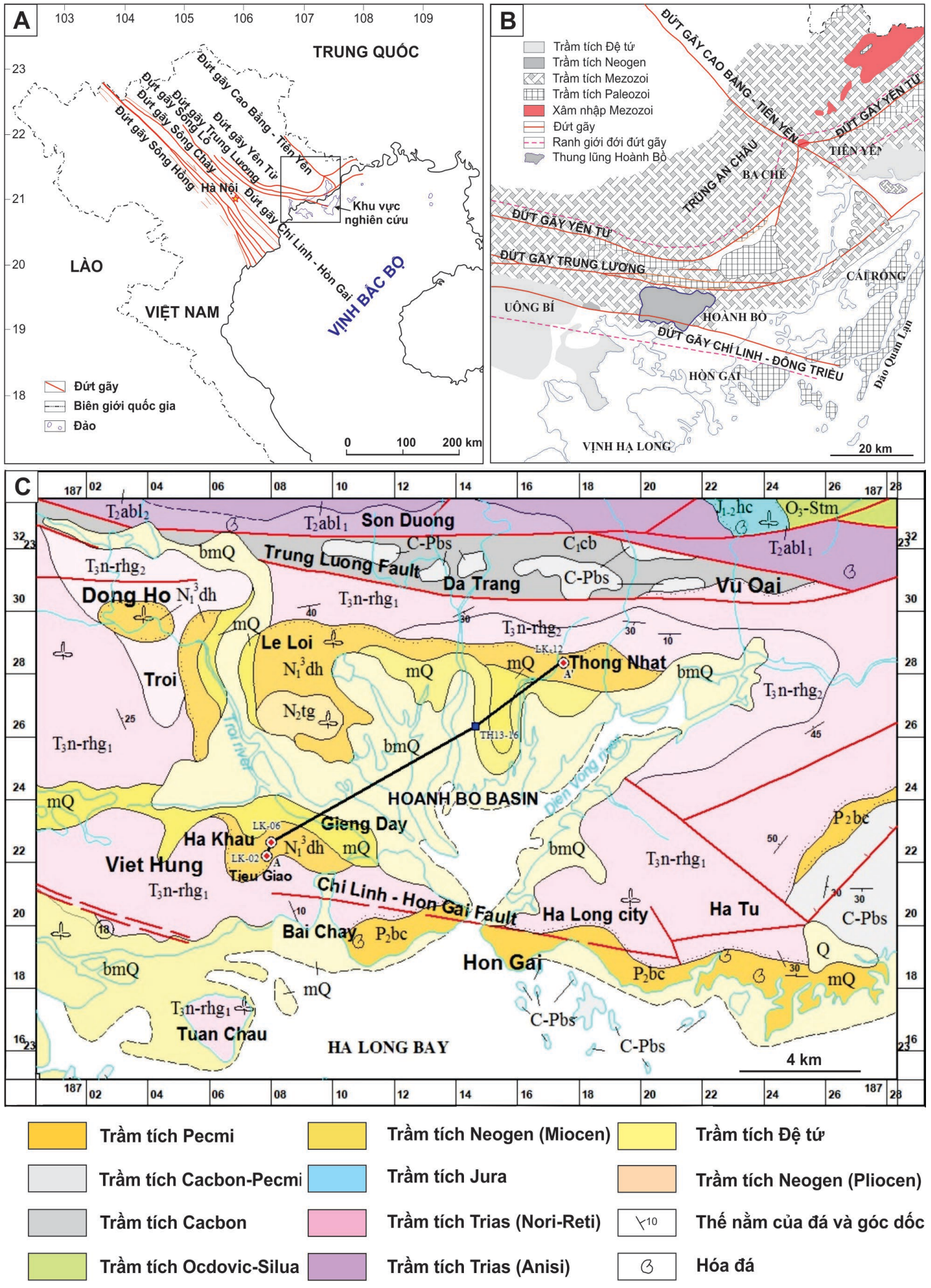

Hình 1. A - So đồ vị trí vùng nghiên cứu nằm về phía đông đới đút gãy Sông Hồng và trong mối liên hệ với các khu vực xung quanh (Dovjikov và nnk., 1965); B - So đồ cấu trúc thể hiện vị trí thung lũng Hoành Bồ, Quảng Ninh trong đói cấu trúc phức nếp lồi Quảng Ninh (theo Trần Đức Lưong và Nguyễn Xuân Bao, 1988); C - So đồ địa chất khu vực Hoành Bồ, Quảng Ninh (theo Lê và nnk., 1996). 
Về tuổi của hệ tầng, Bạch Hiến Canh (trong Dovjikov, 1965) xếp tuổi hệ tầng vào Đệ Tam không phân chia. Không lâu sau đó, Phạm và cộng sự (1969) xếp phân vị địa tầng này vào hệ tầng Tiêu Giao trên cơ sở so sánh địa tầng với các trầm tích Neogen ở Đồng Ho (Uông Bí). Hiện nay, trong các văn liệu địa chất đều đang sử dụng tuổi Neogen của hệ tầng Tiêu Giao theo quan điểm này.

Trầm tích bở dời hệ Đệ Tứ phân bố rộng rãi vùng nghiên cứu, chúng chủ yếu nằm về phía nam dọc các lòng sông, suối ở phần trung và thượng nguồn hoặc trong các thung lũng nằm trong địa hình vùng núi. Thành phần thạch học gồm: cát, cuội, sỏi, sạn, bột, sét có mức độ mài tròn và độ chọn lọc phụ thuộc vào điều kiện thành tạo. Chiều dày hệ tầng $0,5 \div 50 \mathrm{~m}$.

Chi tiết 17 kiểu đá trầm tích với các đặc điểm khác nhau đã được ghi nhận và mô tả riêng lẻ (Hoang và nnk., 2015), chúng gồm các loại như sau: 1) bùn - sạn hỗn hợp (Gb), 2) cuội kết với thành phần mảnh vụn và cát kết $(\mathrm{Gmm}), 3)$ cuội kết phân dị ngược (Gig), 4) cuội kết phân lớp xiên chéo phẳng $(\mathrm{Gp}), 5)$ cuội kết phân lớp sóng xiên $(\mathrm{Gt}), 6)$ cuội kết phân lớp nằm ngang $(\mathrm{Gh}), 7)$ thấu kính cát kết $(\mathrm{Sm}), 8)$ cát kết phân lớp xiên chéo phẳng $(\mathrm{Sp}), 9)$ Cát kết phân lớp sóng xiên (St), 10) cát kết phân lớp xiên chéo gợn sóng $(\mathrm{Sr}), 11)$ cát kết phân lớp nằm ngang (Sh), 12) cát kết phân cấp bình thường (Sng), 13) cát kết phân lớp xiên chéo thoải (SI), 14) cát kết phân phiến, bột kết và đá vôi $(\mathrm{Fl}), 15)$ thấu kính bột kết và đá vôi (Fsm), 16) thấu kính sét kết $(\mathrm{Fm}), 17)$ than (C). Tuy nhiên, để thuận lợi cho quá trình xây dựng dữ liệu và tính toán, bài báo này đã tiến hành tổng hợp thành 3 loại tướng cơ bản: A1) tướng cuội kết; A2) tướng cát kết; A3) tướng hạt mịn và không mảnh vụn, chi tiết trình bày ở Bảng 1 và Hình 2.

\section{Số liệu và phương pháp nghiên cứu}

Chu kỳ của quá trình trầm tích là một khái niệm phổ biến và có nhiều ứng dụng trong các kiểu môi trường trầm tích. Tính chu kỳ của chuỗi trầm tích được định nghĩa là một loạt các đơn vị thạch học hoặc các lớp tướng đá trầm tích được lặp đi, lặp lại liên tiếp nhau theo kiểu tuần hoàn hoặc phân nhịp ở một mức độ nào đó (Duff và nnk., 1967). Hai loại chu kỳ trầm tích đáng chú ý có thể quan sát được đó là: loại chỉ tồn tại duy nhất một trật tự của chuỗi trầm tích; và loại khác có một trật tự lặp đi, lặp lại nhất định theo chiều thẳng đứng. Trong nghiên cứu này, mỗi "lớp trầm tích" cung cấp một đơn vị logic, do đó, việc kiểm tra tính chu kỳ của một chuỗi là phù hợp, để đơn giản cho quá trình tính toán nghiên cứu này không xét đến độ dày của lớp trầm tích (Vistelius và Faas, 1965).

Bảng 1. Số hiệu tướng và các lớp thạch học.

\begin{tabular}{|c|c|c|}
\hline $\begin{array}{c}\text { Tổ hợp tướng trầm } \\
\text { tích }\end{array}$ & $\begin{array}{l}\text { Số hiệu lớp } \\
\text { thạch học }\end{array}$ & Mô tả thạch học \\
\hline \multirow{6}{*}{$\begin{array}{c}\text { A1 } \\
\text { Tướng cuội kết }\end{array}$} & 1 & Bùn - sạn hỗn hợp (Gb) \\
\hline & 2 & Cuội kết với thành phần mảnh vụn và cát kết (Gmm) \\
\hline & 3 & Cuội kết phân dị ngược (Gig) \\
\hline & 4 & Cuội kết phân lớp xiên chéo phẳng (Gp) \\
\hline & 5 & Cuội kết phân lớp sóng xiên (Gt) \\
\hline & 6 & Cuội kết phân lớp nằm ngang (Gh) \\
\hline \multirow{7}{*}{$\begin{array}{c}\mathrm{A} 2 \\
\text { Tướng cát kết }\end{array}$} & 7 & Thấu kính cát kết (Sm) \\
\hline & 8 & Cát kết phân lớp xiên chéo phẳng (Sp) \\
\hline & 9 & Cát kết phân lớp sóng xiên (St) \\
\hline & 10 & Cát kết phân lớp xiên chéo gợn sóng (Sr) \\
\hline & 11 & Cát kết phân lớp nằm ngang (Sh) \\
\hline & 12 & Cát kết phân cấp bình thường (Sng) \\
\hline & 13 & Cát kết phân lớp xiên chéo thoải (Sl) \\
\hline \multirow{4}{*}{$\begin{array}{c}\text { A3 } \\
\text { Tướng hạt mịn } \\
\text { và không mảnh vụn }\end{array}$} & 14 & Bùn kết và bột kết phân lớp (Fl) \\
\hline & 15 & Thấu kính bột kết và đá vôi (Fsm) \\
\hline & 16 & Thấu kính sét kết (Fm) \\
\hline & 17 & Trầm tích than (C) \\
\hline
\end{tabular}



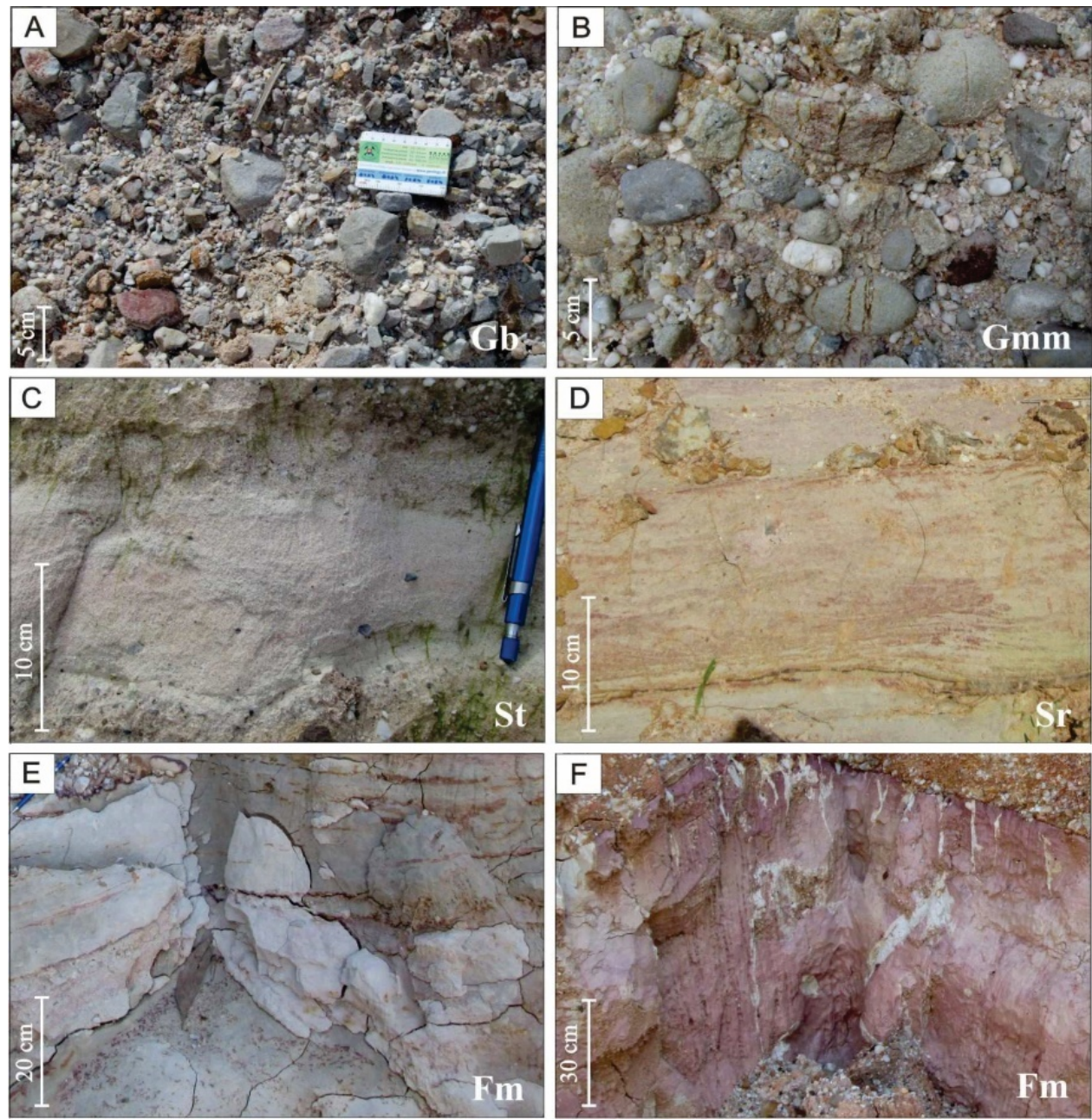

Hình 2. Một số kiểu tướng đá đặc trung khu vực thung lũng Hoành Bồ, $A$ - Bùn - sạn hỗn hợp, B - Cuội kết với thành phần mảnh vụn, $C$ - Cát kết phân lớp sóng xiên, $D$ - Cát kết phân lóp xiên chéo gợn sóng, $E$, F - Thấu kính sét kết (theo Hoang và nnk, 2015).

\subsection{Xây dựng cơ sở dũ liệu cho xích Markov}

Mặt cắt chuỗi trầm tích theo phương thẳng đúng: 12 mặt cắt thiết đồ lỗ khoan (Dương, 1960) đã được xem xét để nghiên cứu sự phân bố của các tướng trầm tích theo phương thẳng đứng và theo đường phương khu vực thung lũng Hoành Bồ.

Bản chất của dũ liệu: dữ liệu được sử dụng cho nghiên cứu là các tướng đá trầm tích khác nhau trong một biểu đồ mã hóa chuỗi trầm tích theo chiều thẳng đứng thành một số trạng thái hữu hạn để phân tích thống kê (Khan và Tewari, 2013). Trong nghiên cứu này, chỉ có ba tướng đá trầm tích cơ bản được sử dụng và đánh dấu rõ ràng ở mặt cắt vết lộ cũng như trong từng biểu đồ trầm tích, điều này cũng được thực hiện nhằm ngăn chặn sự lan truyền chuyển tiếp giữa hai tướng trầm tích (Hota và Maejima, 2004).

Đối với các mối quan hệ thống kê giữa các tướng trầm tích khác nhau, ba biến sau đây được trích xuất từ 12 thiết đồ lỗ khoan thẳng đứng. Biến ba tướng trầm tích và các ký hiệu được sử dụng để chỉ định chúng như Bảng 1 , tất cả ba trạng thái này đều được biểu diễn tốt ở các vết lộ (Hình 2) và thiết đồ lỗ khoan.

Xác định ma trận tần suất xuất hiện (F): ma trận tần suất được tính toán từ mặt cắt chuỗi trầm tích phương thẳng đứng của biểu đồ trầm tích. Xích Markov được sử dụng có thuộc tính ít bộ nhớ hơn, tức là hoàn cảnh địa chất tại điểm $(\mathrm{n}$ - 1) chi phối sự kiện sẽ xảy ra tại n. Đó là lý do tại sao tất cả 12 thiết đồ lỗ khoan có thể được sử dụng để tính toán ma trận $\mathrm{F}$ mà không làm mất thông tin. 
Sau đó, dữ liệu cho tất cả các thiết đồ được bổ sung vào ma trận thiết lập cho thung lũng (Tewari và nnk., 2009). Số lần chuyển tiếp từ tướng thạch học i sang $\mathrm{j}$ được biểu diễn trong hàng i và cột $\mathrm{j}$ của ma trận $\mathrm{F}$, biểu thị số lần trạng thái $\mathrm{j}$ theo ngay sau trạng thái i trong biểu đồ trầm tích.

Ma trận tần suất được xây dựng thành xích Markov ấn định, ma trận chỉ xem xét sự chuyển tiếp về thạch học của lớp mà không xét đến độ dày của chúng. Do vậy, chuyển tiếp về tướng trầm tích được cho là chỉ xảy ra khi thành phần thạch học của chúng thay đổi, các phần tử trên đường chéo đều bằng " 0 " trong ma trận tần suất (Tewari và nnk., 2009).

\subsection{Thủ tục phân tích}

Trong nghiên cứu này, ma trận Markov ấn định được sử dụng để xây dựng ma trận tần suất $\left(F_{i j}\right)$, trong đó $\mathrm{i}, \mathrm{j}$ lần lượt là số hàng và số cột. Khi $i$ $=j$, số 0 có trong ma trận, điều này ngụ ý rằng sự chuyển tiếp từ tướng đá này sang tướng đá khác chỉ được ghi lại khi có sự thay đổi đột ngột trong các tướng. Ưu điểm của ma trận Markov ấn định so với ma trận Markov thông thường là được sử dụng để xác định trật tự thực tế trong quá trình thay đổi tướng đá (nếu có), bất kể độ dày của lớp riêng lẻ (Hota và Maejima, 2004).

\subsubsection{Ma trận tần suất chuyển tiếp (F)}

Đây là một mảng hai chiều ghi lại tần suất xuất hiện của các chuyển tiếp theo phương thẳng đứng, xảy ra giữa các tướng trầm tích khác nhau trong một trình tự địa tầng cho trước. Các tướng bên dưới của mỗi cặp chuyển tiếp được cho bởi các số hàng của ma trận và các tướng bên trên được cho bởi các số cột.

\subsubsection{Ma trận xác suất chuyển tiếp hướng lên (P)}

Ma trận xác suất chuyển tiếp hướng lên tính toán xác suất chuyển tiếp bên trên của các tướng trầm tích trong mỗi mặt cắt và được xác định:

$$
P_{i j}=\frac{F_{i j}}{S_{R_{i}}}
$$

Trong đó: $S_{R i}$ - tổng số hàng tương ứng.

\subsubsection{Ma trận xác suất chuyển tiếp đi xuống (Q)}

Xác suất chuyển tiếp bên dưới được xác định bằng cách chia các phần tử của ma trận tần suất chuyển tiếp $(F)$ cho tổng cột tương ứng, tức là:

$$
Q_{i j}=\frac{F_{i j}}{S_{C_{j}}}
$$

Trong đó: $S_{C j}$ - tổng số cột. Nó tính toán xác suất chuyển tiếp bên dưới của các tướng trầm tích trong một phân vị địa tầng nhất định, tức là xác suất của các tướng i được thay thế bởi các tướng j.

\subsubsection{Ma trận thử nghiệm độc lập $(R)$}

Ma trận này đại diện cho xác suất của quá trình chuyển tiếp đã cho xảy ra theo cách ngẫu nhiên, được xác định theo công thức:

$$
R_{i j}=\frac{S_{C_{j}}}{S_{T}-S_{R_{i}}}
$$

Trong đó: $S_{T}$ đại diện cho tổng số lần chuyển đổi tướng. Các ô trên đường chéo được lấp đầy bởi các số 0 , giả sử mỗi lần chuyển tiếp đại diện cho một sự thay đổi đột ngột trong đặc điểm tướng.

\subsubsection{Ma trận vi sai (D)}

Ma trận vi sai được tính toán để làm nổi bật những chuyển đổi có xác suất xảy ra lớn hơn nếu chuỗi là ngẫu nhiên. Bằng cách liên kết các giá trị dương của ma trận vi sai, một đường hướng lên ưu tiên của các chuyển tiếp tướng có thể được xây dựng, chúng được giải thích theo các quá trình lắng đọng dẫn đến sự sắp xếp cụ thể của các tướng này (Miall, 1973).

$$
D_{i j}=P_{i j}-R_{i j}
$$

Giá trị dương trong ma trận vi sai chỉ ra một quá trình chuyển tiếp cụ thể xảy ra thường xuyên hơn và giá trị âm ngụ ý sự chuyển tiếp xảy ra ít thường xuyên hơn. Trong ma trận vi sai, các giá trị trong mỗi hàng của ma trận tổng bằng 0 . Nếu các giá trị gần bằng 0 , một phân vị địa tầng theo phương thẳng đứng có ít hoặc không có "bộ nhớ" cho biết bản chất độc lập của sự trầm tích các tướng trong một thung lũng.

\subsubsection{Ma trận tần suất kỳ vọng (E)}

Tần suất kỳ vọng, ma trận đại diện cho số lần dự kiến chuyển tiếp từ tướng i sang tướng $\mathrm{j}$ và được xác định bởi:

$$
E_{i j}=R_{i j} \times S_{R_{i}}
$$

Trong đó: $E_{i j}$ - ma trận tần suất kỳ vọng; $\mathrm{R}_{\mathrm{ij}}$ ma trận thử nghiệm độc lập; $S_{R i}$ - tổng số hàng 
tương ứng.

\subsubsection{Kiểm tra múc ý nghĩa}

Tiêu chuẩn kiểm tra chi bình phương $\left(\chi^{2}\right)$ cho tham số được áp dụng nhằm xác định phân vị địa tầng đã cho có "bộ nhớ" Markov hay không, nghĩa là quá trình trầm tích có mang tính lặp lại chu kỳ hay không. Để kiểm tra giả thuyết rỗng, các giá trị $\chi^{2}$ được tính toán cho các phân vị địa tầng theo phương thẳng đứng.

$$
\chi^{2}=\sum_{i=0}^{n} \sum_{j=0}^{n} \frac{\left(F_{i j}-E_{i j}\right)^{2}}{E_{i j}}
$$

Trong đó: $F_{i j}$ - ma trận xác định số lần chuyển tiếp hoặc tần suất quan sát của các phần tử trong ma trận số lần chuyển tiếp; $E_{i j}$ - ma trận tần suất kỳ vọng; $v$ - bậc tự do cho trước $\left(n^{2}-2 n\right) ; n$ - biểu thị hạng của ma trận.

Nếu giá trị được tính toán theo tiêu chuẩn $\chi^{2}$ lớn hơn giá trị giới hạn ở mức ý nghĩa $0,5 \%$ cho thấy quá trình trầm tích tuân theo quy luật Markov và các tướng đá trầm tích được sắp xếp tuần hoàn trong vùng nghiên cứu.

\subsection{Khái niệm entropy}

Khái niệm entropy đối với phân vị địa tầng trầm tích được áp dụng để xác định mức độ xuất hiện ngẫu nhiên của các tướng trầm tích trong phân vị địa tầng. Hattori (1976) đã nhận dạng hai loại entropy đối với mỗi trạng thái thạch học: một là entropy sau trầm tích tương ứng với ma trận $(\mathrm{P})$ và một là entropy trước trầm tích tương ứng với ma trận (Q).

Hattori (1976) đã định nghĩa entropy sau trầm tích tương ứng tướng trầm tích ở trạng thái i xác định như sau:

$$
E_{i}^{(\text {post })}=-\sum_{j=0}^{n} P_{i j} \times \log \left(P_{i j}\right)
$$

Trong đó: $E_{i}\left(\right.$ post) - entropy sau trầm tích; $P_{i j}$ ma trận xác suất chuyển tiếp hướng lên.

Entropy trước trầm tích tương ứng trạng thái tướng trầm tích i là:

$$
E_{i}^{(\text {pre })}=-\sum_{j=0}^{n} Q_{i j} x \log \left(Q_{i j}\right)
$$

Trong đó: $E_{i}($ pre) - entropy trước trầm tích;

$Q_{i j}$ - ma trận xác suất chuyển tiếp đi xuống.

Giá trị lớn của entropy biểu thị rằng tướng $\mathrm{i}$ xuất hiện độc lập với trạng thái liền kề. Hai entropy cùng nhau tạo thành một tập entropy cho trạng thái i và đóng vai trò là chỉ thị cho sự đa dạng của quá trình chuyển tiếp thạch học ngay sau và trước khi xuất hiện trạng thái i tương ứng.

Mối quan hệ qua lại của sau entropy và trước entropy được sử dụng để phân loại các thông số chu kỳ khác nhau thành các chu trình bất đối xứng, đối xứng và ngẫu nhiên (Hattori, 1976). Giá trị của entropy tăng lên cùng với số các tướng thạch học. Để loại bỏ ảnh hưởng này, chuẩn hóa các entropy được thực hiện theo phương trình sau.

$$
E_{n}=\frac{E}{E_{\max }} \text {, vói } E_{\max }=-\log _{2}\left(\frac{1}{n-1}\right)
$$

Trong đó: $E_{n}$ - entropy được chuẩn hóa; E hoặc là entropy sau trầm tích hoặc entropy trước trầm tích; $E_{\max }$ - entropy lớn nhất có thể có trong một hệ thống mà biến trạng thái n hoạt động.

\section{Kết quả và thảo luận}

Các ma trận dùng để phân tích sự chuyển tiếp của các tướng thạch học ở thung lũng Hoành Bồ được tính toán sử dụng phương pháp và các công thức đã trình bày ở trên các Bảng $2 \div 9$.

\subsection{Phân tích xích Markov}

Điều quan trọng là các chuyển tiếp tướng đá đại diện cho các chuyển đổi tướng trầm tích có thể xảy ra nhất, nhưng không phải là tần suất thực tế của chúng trong các chuỗi trầm tích được nghiên cứu. Ma trận chuyển tiếp tướng quan sát chứa các tần suất thực sự của chuyển tiếp tướng thạch học. Các giá trị cao nhất của $(\mathrm{P})$ và các giá trị dương của (D) đã được tính đến để xác định các quá trình tuần hoàn (Maria và nnk., 2014). Nó đảm bảo rằng trong khi giải thích sự chuyển tiếp tướng trầm tích, cả quá trình chuyển đổi tướng có ý nghĩa thống kê và chuyển đổi tướng thực sự đều được tính đến để hiểu rõ hơn ý nghĩa của chúng và quá trình trầm tích ở phân vị địa tầng được xem xét.

Bảng 2. Ma trận tần suất chuyển tiếp (F).

\begin{tabular}{|c|c|c|c|c|c|}
\hline & $\mathrm{A} 1$ & $\mathrm{~A} 2$ & $\mathrm{~A} 3$ & $\mathrm{~S}_{\mathrm{Ri}}$ & $\mathrm{T}-\mathrm{S}_{\mathrm{Ri}}$ \\
\hline $\mathrm{A} 1$ & 0 & 12 & 0 & 12 & 14 \\
\hline $\mathrm{A} 2$ & 11 & 0 & 1 & 12 & 14 \\
\hline $\mathrm{A} 3$ & 1 & 1 & 0 & 2 & 24 \\
\hline $\mathrm{S}_{\mathrm{C} j}$ & 12 & 13 & 1 & \multicolumn{2}{|c|}{ Tổng $=26$} \\
\hline
\end{tabular}


Bảng 3. Ma trận xác suất chuyển tiếp hướng lên (P).

\begin{tabular}{|c|c|c|c|}
\hline & A1 & A2 & A3 \\
\hline A1 & 0 & 1 & 0 \\
\hline A2 & 0,917 & 0 & 0,083 \\
\hline A3 & 0,5 & 0,5 & 0 \\
\hline
\end{tabular}

Bảng 4. Ma trận xác suất chuyển tiếp đi xuống (Q).

\begin{tabular}{|c|c|c|c|}
\hline & A1 & A2 & A3 \\
\hline A1 & 0 & 0,917 & 0,083 \\
\hline A2 & 0,923 & 0 & 0,077 \\
\hline A3 & 0 & 1 & 0 \\
\hline
\end{tabular}

Bảng 5. Ma trận xác suất thử nghiệm độc lập (R).

\begin{tabular}{|c|c|c|c|}
\hline & A1 & A2 & A3 \\
\hline A1 & 0 & 0,929 & 0,071 \\
\hline A2 & 0,857 & 0 & 0,071 \\
\hline A3 & 0,500 & 0,542 & 0 \\
\hline
\end{tabular}

Bảng 6. Ma trận vi sai (D).

\begin{tabular}{|c|c|c|c|}
\hline & A1 & A2 & A3 \\
\hline A1 & 0 & 0,071 & $-0,071$ \\
\hline A2 & 0,060 & 0 & 0,012 \\
\hline A3 & 0 & $-0,042$ & 0 \\
\hline
\end{tabular}

Bảng 7. Ma trận tần suất kỳ vọng (E).

\begin{tabular}{|c|c|c|c|}
\hline & A1 & A2 & A3 \\
\hline A1 & 0 & 11,143 & 0,857 \\
\hline A2 & 10,286 & 0 & 0,857 \\
\hline A3 & 1 & 1,083 & 0 \\
\hline
\end{tabular}

Bảng 8. Kiểm tra múc ý nghĩa $\left(\chi^{2}\right)$.

\begin{tabular}{|c|c|c|c|}
\hline $\begin{array}{c}\text { Phương } \\
\text { trình } \\
\text { kiểm tra }\end{array}$ & $\begin{array}{c}\text { Giá trị } \\
\text { tính } \\
\text { toán }\end{array}$ & $\begin{array}{c}\text { Giá tri giới hạn } \\
\text { tại mức ý } \\
\text { nghĩa 0,5\% }\end{array}$ & $\begin{array}{c}\text { Mức tự } \\
\text { do }\end{array}$ \\
\hline Hoành Bồ & 0,998 & 2,366 & 3 \\
\hline
\end{tabular}

Bảng 9. Ma trận sử dụng phân tích giá trị entropy của các tướng đá thung lũng Hoành Bồ.

\begin{tabular}{|c|c|c|c|c|}
\hline & $E_{\text {Post }}$ & $E_{\text {Pre }}$ & $E_{\text {nPost }}$ & $E_{\text {nPre }}$ \\
\hline A1 & 0 & 0,287 & 0 & 0,287 \\
\hline A2 & 0,287 & 0,271 & 0,287 & 0,271 \\
\hline A3 & 0,693 & 0 & 0,693 & 0 \\
\hline
\end{tabular}

Giá trị tính toán $\chi^{2}$ cho thung lũng Hoành Bồ thấp hơn giá trị giới hạn tại mức ý nghĩa 0,5\%, điều này có nghĩa là giả thuyết sai, cho thấy sự lắng đọng trầm tích không tuân theo luật Markov và sự lắng đọng các lớp trầm tích không theo chu kỳ (Bảng 8). Con đường chuyển tiếp đi lên được ưu tiên cho các tướng trầm tích là: $\mathrm{A} 1 \rightarrow \mathrm{A} 2 \rightarrow \mathrm{A} 3$.

Sự chuyển tiếp giữa các tướng đá không tuân theo quá trình Markov và có bản chất nguồn gốc không lặp lại. Mục đích rõ ràng của phương pháp này là phát hiện và xác định các mối quan hệ tuần hoàn (nếu có). Tuy nhiên, tính chu kỳ là vắng mặt hoặc rất yếu trong nghiên cứu này, đây là thông tin có thể hỗ trợ rất nhiều trong việc luận giải môi trường trầm tích thung lũng Hoành Bồ.

\subsection{Phân tích entropy}

Theo kết quả tính toán ở Bảng 9 , cả $\mathrm{E}_{\text {pre và }} \mathrm{E}_{\text {pos }}$ $\geq 0$ ngụy cả ba tướng trầm tích $(A 1, A 2$, và $A 3)$ đều bị phủ và chúng cũng có thể bị che khuất bởi nhiều hơn một trạng thái tướng đá khác (Hattori, 1976). Đối với các tướng $A 2$ và $A 3, E_{\text {post }}>E_{\text {pre }}$ điều đó cho phép suy ra rằng dòng chảy của cát và sét vào thung lũng Hoành Bồ là sự kiện ngẫu nhiên nhất. Đối với tướng $A 1, E_{p r e}>E_{\text {post }}$ mối quan hệ này chỉ ra rằng cuội kết, sạn kết có thể tích tụ trong nhiều loại môi trường trầm tích khác nhau và gây ảnh hưởng mạnh mẽ đáng kể đến việc lựa chọn trạng thái của tướng đá kế tiếp nó.

Sự khác biệt về $\mathrm{E}_{\text {Pre }}$ và $\mathrm{E}_{\text {Post }}$ và mối quan hệ $\mathrm{E}_{\text {Pre }}$ $<$ Epost trong trường hợp tướng A2, A3 cho thấy sự phụ thuộc mạnh mẽ vào nguồn vật liệu ban đầu (Bảng 8). Mô hình lắng đọng trầm tích ở tướng $\mathrm{A} 1$, $E_{\text {Pre }}>E_{\text {Post }}$ là dấu hiệu của năng lượng thấp, các vật liệu trầm tích bị bỏ lại trên đường vận chuyển ở giai đoạn suy yếu của chu kỳ trầm tích. Nói cách khác, tướng trầm tích này lắng đọng trong môi trường nằm ở phần xa của thung lũng thay vì ở các khu vực khác. Các chu kỳ trầm tích của thung lũng Hoành Bồ thuộc loại chu trình entropy cực đại hoặc entropy gần bờ, biểu thị bằng chấm đen trền Hình 3.

\subsection{Mô hình dòng trầm tích}

Trong thung lũng Hoành Bồ, trình tự trầm tích bất đối xứng liên quan đến việc gián đoạn trầm tích. Các lớp trầm tích mỏng dần theo hướng đi lên đại diện cho trầm tích đầm hồ, trong khi các lớp trầm tích theo xu hướng dày dần lên, đại diện cho trầm tích bãi cát phẳng cửa sông. Sự thay đổi về độ dày của lớp gợi ý đến sự lắng đọng do dòng chảy không ổn định ở chế độ sông, kênh rạch. Dòng chảy đột ngột bị cản trở kết quả ở năng lượng của vật liệu trầm tích giảm nhanh và đưa đến sự lắng đọng nhanh chóng. Chế độ năng lượng cực đại của khu vực được suy ra từ tổng phân tích entropy cho thấy rằng chuỗi không phải là chuỗi 


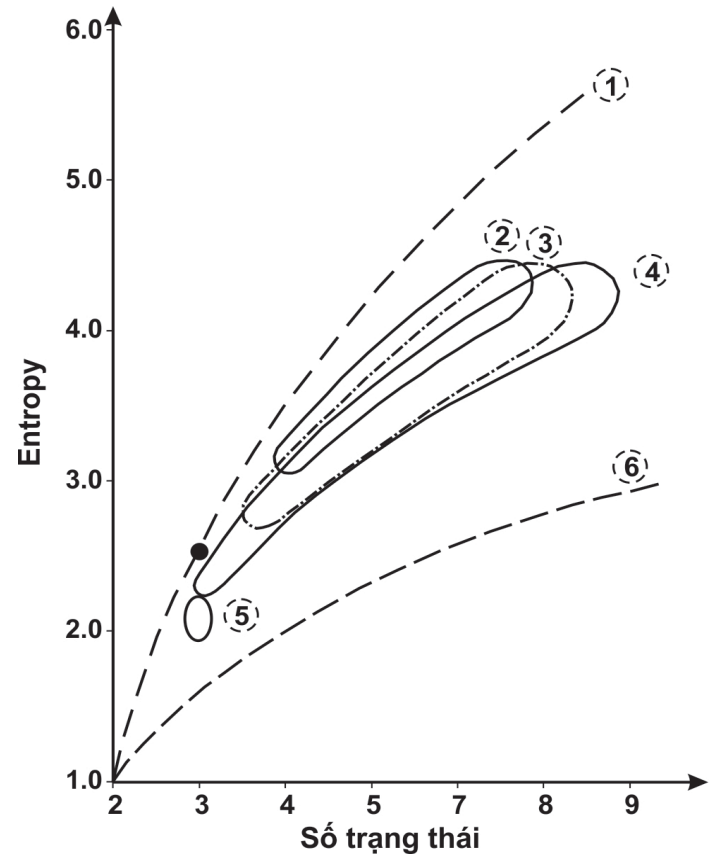

Hình 3. Mối quan hẹ giữa entropy và các môi truờng trầm tích của chuỗi thạch học (theo Hattori, 1976), chấm đen là chu kỳ entropy cực đại; 1 - entropy lón nhất; 2 - entropy cho trầm tích than; 3 - entropy cho trầm tích sông - bãi bồi; 4 entropy cho trầm tích gần bò̀; 5 - entropy cho trầm tích flysch; 6 - entropy nhỏ nhất.

trầm tích biển và mô hình dòng chảy tổng thể thay đổi từ môi trường sông sang môi trường đầm hồ.

Tướng trầm tích cuội kết (A1) đại diện cho các trầm tích sông, hoặc nón phóng vật với các bằng chứng như mảnh vỡ cuội, sạn khá tròn cạnh, cuội kết phân lớp xiên chéo phẳng. Tướng cát kết (A2) với các đặc điểm hạt trầm tích kích thước lớn, độ chọn lọc kém, đa nguồn thường đại diện cho các vật liệu trầm tích trong môi trường châu thổ. Tướng trầm tích $\mathrm{A} 3$ được đặc trưng bởi các lớp hạt mịn với màu chủ đạo là xám đến xám đen và có tính phân nhịp. Từ các đặc điểm này cho thấy trầm tích ở đây được thành tạo từ nguồn vật liệu giàu vật chất hữu cơ (chủ yếu là thực vật) và ít mảnh vụn, môi trường yên tĩnh, chúng gợi ý một môi trường trầm tích kiểu đầm hồ. Giai đoạn lắng đọng trầm tích tướng $\mathrm{A} 3$ được kết nối với quá trình trầm tích ngày nay, được đặc trưng bởi các trầm tích ít gắn kết. Trong một thời gian dài, vật liệu trầm tích điển hình đã bị kiểm soát bởi hoạt động kiến tạo và sự suy thoái của mực nước biển do biến đổi khí hậu. Chiều dày lớp trầm tích có xu hướng ngày càng dày dần về phía vịnh Hạ Long.
Hiện nay, gần như toàn bộ khu vực thung lũng Hoành Bồ được phủ bởi tướng hỗn hợp đầm lầy thủy triều biển. Trầm tích của tướng A3 được phân bố phổ biến quanh vịnh Cửa Lục, đặc điểm điển hình của tướng này là sự phát triển của các đầm lầy ngập mặn. Chế độ năng lượng liên quan đến tổng entropy gợi ý rằng đá tướng hạt mịn, không mảnh vụn ở phần xa của thung lũng không phải là nguồn gốc biển. Mô hình dòng chảy thay đổi tổng thể từ môi trường sông sang môi trường đầm hồ.

\section{Kết luận}

Khu vực thung lũng Hoành Bồ phổ biến các thành tạo cuội kết, cát kết, sét kết thuộc hệ tầng Đồng Ho và Tiêu Giao với nhiều kiểu tướng trầm tích. Sử dụng xích Markov và hàm Entropy cho phép nghiên cứu quy luật tướng trầm tích từ các vết lộ và thiết đồ lỗ khoan vùng nghiên cứu. Kết quả cho phép rút ra những nét chính như sau:

1) Việc áp dụng xích Markov ấn định cho 12 thiết đồ lỗ khoan nhận được một đường chuyển tiếp hướng lên thường thích hợp hơn cho các lớp trầm tích. Các quá trình thành tạo trầm tích không mang tính Markov hoặc độc lập trong tự nhiên;

2) Mức năng lượng của dòng chảy trong toàn bộ quá trình hình thành thung lũng cho thấy một sự dao động đáng kể được phản ánh bởi phân tích entropy với sự thay đổi của môi trường trầm tích. Sự thay đổi về độ dày lớp và trình tự không đối xứng của chuỗi trầm tích gợi ý một quá trình trầm tích do dòng chảy không ổn định ở chế độ sông ngòi, kênh. Dòng chảy đột ngột bị cản trở, kết quả là năng lượng của dòng chảy mang vật liệu giảm nhanh dẫn đến sự trầm tích nhanh chóng;

3) Trình tự các tướng theo thứ tự từ dưới lên trên gồm: tướng cuội kết (A1) đại diện cho các trầm tích sông, hoặc nón phóng vật với các bằng chứng như mảnh vỡ cuội, sạn khá tròn cạnh, cuội kết phân lớp xiên chéo phẳng. Tướng cát kết $(\mathrm{A} 2)$ với các đặc điểm kích thước hạt lớn, độ chọn lọc kém, đa nguồn, chúng thường đại diện cho các vật liệu trầm tích trong môi trường sông. Tướng trầm tích (A3) được đặc trưng bởi các lớp hạt mịn với màu chủ đạo là xám đến xám đen và có tính phân nhịp, cho thấy trầm tích được thành tạo từ nguồn vật liệu giàu vật chất hữu cơ (chủ yếu là thực vật) và được lắng đọng trong môi trường tĩnh - môi trường đầm hồ; 
Chế độ năng lượng liên quan đến tổng entropy gợi ý rằng đá tướng hạt mịn, không mảnh vụn ở phần xa của thung lũng không phải là nguồn gốc biển. Mô hình dòng chảy thay đổi tổng thể từ môi trường sông sang môi trường đầm hồ;

4) Kết quả của nghiên cứu này cho thấy trình tự trầm tích trong thung lũng Hoành Bồ là không tuần hoàn, phi Markov và đặc điểm không đối xứng. Như vậy, việc ứng dụng xích Markov và hàm Entropy trong nghiên cứu tướng đá trầm tích đã chứng tỏ vai trò không thể thiếu trong việc nghiên cứu, lý giải môi trường và quá trình trầm tích trong khu vực.

\section{Đóng góp của các tác giả}

Khương Thế Hùng - thực hiện nghiên cứu, tổng hợp số liệu và xây dựng cơ sở dữ liệu, cũng như luận giải, phân tích và đánh giá vấn đề thảo luận; Lại Thị Thúy Trà - thực hiện xây dựng và giải các thuật toán về xích Markov và hàm Entropy, cũng như lý giải ý nghĩa của số liệu tính toán.

\section{Tài liệu tham khảo}

C Cao, W., Zhou, A., \& Shen, S. L. (2022). An analytical method for estimating horizontal transition probability matrix of coupled Markov chain for simulating geological uncertainty. Computers and Geotechnics, 29, 103-147.

Đặng, T. H. (cb) (2007). Địa tầng các trầm tích Phanerozoi ở Đông Bắc Bộ. Viện Địa chất và Khoáng sản Việt Nam, 413 trang.

Doktor, M., Krawczyk, A., \& Mastej, W. (2010). Testing the randomness of lithostratigraphic successions with the markov chain methods. Annales Societatis Geologorum Poloniae, 80, 163-166.

Dovjikov, A. E. (cb). (1965). Địa chất miền bắc Việt Nam. Tổng cục Địa chất và Khoáng sản Việt Nam.

Duff, P., McL. D., Hallam, A., \& Walton, E.K. (1967). Cyclic sedimentation. Elsevier Publishing Company, Amsterdam.

Dương, T. P. (1960). Tìm kiếm xung quanh mỏ Đá Dầu Đồng Ho huyện Hoành Bồ, tỉnh Quảng Yên tỷ lẹ 1:25,000. Tổng cục Địa chất và Khoáng sản Việt Nam, 23 trang.
Hoang, V. T., Wysocka, A., Phan, D.P., Nguyen, Q. C., \& Ziółkowski, P. (2015). Lithofacies and depositional environments of the Paleogene/Neogene sediments in the Hoanh Bo Basin (Quang Ninh province, NE Vietnam).Geology, Geophysics and Environment, 41(4).

Hattori, I. (1976). Entropy in Markov chain and discrimination of cyclic pattern in lithologic successions. Mathematical Geology, 8(4), 477497.

Hota, R. N., \& Maejima, W. (2004). Comparative study of cyclicity of lithofacies in Lower Gondwana formations of Talchir basin, Orissa, India: A statistical analysis of subsurface logs. Gondwana Research, 7, 353-362.

Khan, Z. A., \& Tewari, R. C. (2013). Geo-statistical analysis of the Barakar cyclothems (Early Permian): A case study from the subsurface logs in Singrauli Gondwana Sub - basin of Central India. International Journal of Geology, Earth \& Environmental Sciences, 3, 1-22.

Krumbein, W. C. (1967). Fortran IV computer programs for Markov chain experiments in geology. Kansas Geological Survey, Computer Contributions, 13, 1-38.

Lê, H. (cb) (1996). Báo cáo đo vẽ địa chất và khoáng sản tỷ lệ 1:50,000 nhóm tờ Cẩm Phả, Quảng Ninh. Viện Địa chất và Khoáng sản Việt Nam.

Lê, T. V. (2003). Đặc điểm kiến trúc và địa động lực các trũng Kainozoi miền Bắc Việt Nam. Luận án tiến sỹ, Đại học Mỏ - Địa chất, 152 trang.

Miall, A. D. (1973). Markov chain analysis applied to an ancient alluvial plain succession. Sedimentology, 20, 347-364.

Nguyễn, Đ. T. (2004). Nghiên cứu chuyển động kiến tạo hiện đại đới đứt gãy Chí Linh - Đông Triều. Tạp chí các Khoa học về trái đất, 26(4), 587-597.

Phạm, Q. T., Đỗ, B., Nguyễn, Q. A., Đặng, V. K., \& Đỗ, V. H. (1999). Tài liệu mới về Bào tử phấn hoa trong hệ tầng Đồng Ho. Tạp chí Dầu khí, 3, 2-8.

Phạm. V. Q. (cb.). (1969). Tuổi của các trầm tích chứa than Hòn Gai và sự phát triển của địa chất khu vực trong Mezozoi. Tạp chí Địa chất, 13-39. 
Potter, P. E., \& Blakely, R. F. (1968). Random process and lithological transitions. Journal of Geology, 76, 154-170

Schwarzacher, W. (1969). The use of Markov chains in the study of sedimentary cycles. Journal Mathematical Geology, 1, 17-39.

Soto, M. B., Durán, E. L., \& Aldana, M. (2014). Stratigraphic Columns Modeling and Cyclicity Analysis of the Misoa Formation, Maracaibo Lake, Venezuela, using Markov Chains. Geofísica Internacional, 53(3), 277-288.

Tewari, R. C, Singh, D. P., \& Khan, Z. A. (2009). Application of Markov chain and Entropy analysis to lithologic succession - an example from early Permian Barakar Formation, Bellampalli coalfield, Andhra Pradesh, India. Journal of Earth System Science, 18, 583-596.

Tống, D. T., Vũ, K. (cb.). (2005). Các phân vị địa tầng Việt Nam. Trung tâm thông tin Khoa học và Công nghệ, Hà Nội.
Trần, Đ. N., \& Trinhh, D. (1975). Nhũng kết quả mới về nghiên cứu sinh địa tầng các trầm tích Neogen miền Đông Bắc Bộ. CTNCDT: 244 - 283, Nhà xuất bản Khoa học Kỹ thuật Hà Nội.

Trần, Đ. L., \& Nguyễn, X. B. (1988). Bản đồ địa chất Việt Nam tỷ lệ 1:500,000. Tổng cục Địa chất và Khoáng sản Việt Nam.

Trần, V. T., \& Vũ, K. (cb.). (2009). Địa chất và tài nguyên khoáng sản Việt Nam. Nhà xuất bản Khoa học Tự nhiên và Kỹ thuật, 589 trang.

Vistelius, A. B., \& Faas, A. V. (1965). Variation in thickness of strata in the south Urat Paleozoic flysch section. Doklady Akademii Nauk SSSR, 164, 77-79.

Vistelius, A. B., \& Feygelson, T. S. (1965). Theory of formation of sedimentary beds. Doklady Akad Nauk USSR, 164(1), 158-160.

Vũ, V. C. (2002). Đặc điểm đứt gãy tân kiến tạo vùng Đông Bắc Việt Nam. Luận án tiến sỹ. Viện Địa chất, Viện Hàn lâm khoa học và Công nghệ Việt Nam (VAST), Hà Nội, 209 trang. 